\title{
High-fat feeding rapidly induces obesity and lipid derangements in C57BL/6N mice
}

\author{
Christine Podrini · Emma L. Cambridge $\cdot$ Christopher J. Lelliott • \\ Damian M. Carragher · Jeanne Estabel • Anna-Karin Gerdin • Natasha A. Karp • \\ Cheryl L. Scudamore $\cdot$ Sanger Mouse Genetics Project $\cdot$ Ramiro Ramirez-Solis • \\ Jacqueline K. White
}

Received: 6 December 2012/Accepted: 11 April 2013/Published online: 28 May 2013

(c) The Author(s) 2013. This article is published with open access at Springerlink.com

\begin{abstract}
C57BL/6N (B6N) is becoming the standard background for genetic manipulation of the mouse genome. The $\mathrm{B} 6 \mathrm{~N}$, whose genome is very closely related to the reference C57BL/6J genome, is versatile in a wide range of phenotyping and experimental settings and large repositories of B6N ES cells have been developed. Here, we present a series of studies showing the baseline characteristics of B6N fed a high-fat diet (HFD) for up to 12 weeks. We show that HFD-fed B6N mice show increased weight gain, fat mass, and hypercholesterolemia compared to control diet-fed mice. In addition, HFD-fed B6N mice display a rapid onset of lipid accumulation in the liver with both macro- and microvacuolation, which became more severe with increasing duration of HFD. Our results suggest that the $\mathrm{B} 6 \mathrm{~N}$ mouse strain is a versatile background for studying diet-induced metabolic syndrome and may also represent a model for early nonalcoholic fatty liver disease.
\end{abstract}

Electronic supplementary material The online version of this article (doi:10.1007/s00335-013-9456-0) contains supplementary material, which is available to authorized users.

C. Podrini - E. L. Cambridge · C. J. Lelliott ·

D. M. Carragher · J. Estabel · A.-K. Gerdin .

N. A. Karp - Sanger Mouse Genetics Project

R. Ramirez-Solis · J. K. White $(\bowtie)$

Wellcome Trust Sanger Institute,

Wellcome Trust Genome Campus, Hinxton,

Cambridgeshire CB10 1SA, UK

e-mail: jkw@sanger.ac.uk

Present Address:

C. Podrini

Epigenetics of Fatty Liver Disease Research Group,

Institute of Hepatology, Foundation for Liver

Research, 69-75 Chenies Mews, London

WC1E 6HX, UK

\section{Introduction}

The development of transgenic and knockout mouse technologies has facilitated the production of models that have greatly increased our knowledge of disease mechanisms. Combined with the complete sequencing and annotation of the mouse genome (Waterston 2002), we now have unprecedented power to understand the mammalian genome and vertebrate gene function. It is now possible to design and generate virtually any rearrangement in the mouse genome. This process of allele design, mouse generation, and phenotypic analysis is the concept that is currently powering the attempts of global consortia to provide a resource of embryonic stem (ES) cells (Guan et al. 2010; Skarnes et al. 2011), mutant mice, and phenotypic data that is available to the scientific community (Ramírez-Solis et al. 2012).

Originally, ES cells from the 129 background were preferred due to their ease of genetic manipulation. However, 129 mice suffer from poor breeding performance (Seong et al. 2004), substantial genetic divergence (Simpson et al. 1997), and behavioural and metabolic abnormalities

Present Address:

D. M. Carragher

Division of Immunoregulation, MRC National

Institute for Medical Research (NIMR), The Ridgeway,

Mill Hill, London NW7 1AA, UK

C. L. Scudamore

Department of Pathology and Infectious Diseases,

Royal Veterinary College, Hawkshead Lane, North Mymms,

Hatfield, Hertfordshire AL9 7TA, UK

Present Address:

C. L. Scudamore

MRC Harwell, Harwell Science and Innovation

Campus, Harwell, Oxfordshire OX11 ORD, UK 
(Bachmanov et al. 2001; Eisener-Dorman et al. 2009), so that phenotypic assessment is frequently performed on genetically modified 129 mice backcrossed to strains such as the highly characterised C57BL/6J (B6J). ES cells derived from the C57BL/6N (B6N) background retain a closely related genome compared to the reference B6J strain (Waterston 2002) and display a better morphology and growth than B6J-derived ES cells (Pettitt et al. 2009). The International Knockout Mouse Consortium (IKMC) (http:// www.knockoutmouse.org/), determined that B6N ES libraries carrying knockout-first conditional-ready alleles should be developed (Guan et al. 2010; Skarnes et al. 2011). Whilst superficially identical, B6N and B6J lines show phenotypic differences in behaviour, pain sensitivity, rotarod performance (Bryant et al. 2008), fear conditioning (Stiedl et al. 1999), and responses to ethanol consumption (Datta et al. 2008; Khisti et al. 2006). There are also a number of known genetic differences between B6N and B6J. For example, B6N mice lack a mutation of nicotinamide nucleotide transhydrogenase $(\mathrm{Nnt})$ that is found in the B6J substrain (Freeman et al. 2006; Toye et al. 2005) (http:// www.taconic.com/user-assets/Documents/Nnt_Mutation.pdf), and it harbours a mutation in the $\mathrm{Crbl}$ gene that is absent in B6J mice and which affects ocular-induced mutant phenotypes (Mattapallil et al. 2012). Further variations in gene expression and function are likely to exist since the number of SNPs, indels, and structural variants differing between B6N and B6J is estimated to be on the order of tens of thousands (Keane et al. 2011; Yalcin et al. 2011).

With B6N becoming the strain of choice for genetic modifications, the baseline characteristics of this genetic background must be ascertained in order to assess its suitability for different phenotyping tests and to understand the response and variability of the strain to each procedure. B6J mice are susceptible to high-fat-diet-induced obesity, glucose intolerance, and insulin resistance and develop hepatic steatosis during caloric overload (Rossmeisl et al. 2003; West et al. 1992). Here, we investigate the $\mathrm{B} 6 \mathrm{~N}$ response to varying durations of high-fat diet (HFD) in order to obtain baseline data which will be of use to the wider scientific community. We also identify potential utility for the B6N in studies of liver steatosis and the early stages of nonalcoholic fatty liver disease (NAFLD), a clinically relevant condition defined as hepatic steatosis in the absence of a secondary disease (Stickel and Hellerbrand 2010).

\section{Materials and methods}

Animals

One hundred fifty male and 60 female C57BL/6NTac mice from our in-house production colony were used in these studies. Mice were housed at a density of five animals per cage in polysulfone individually ventilated cages [Tecniplast Seal Safe 1284L (overall dimensions of caging $(\mathrm{L} \times \mathrm{W} \times \mathrm{H}$ ): $365 \times 207 \times 140 \mathrm{~mm}$, floor area $\left.\left.=530 \mathrm{~cm}^{2}\right)\right]$ with sterilised Aspen bedding substrate and standard environmental enrichment, in a specific pathogen-free unit. The light cycle was maintained at 12-h light/12-h dark with lights off at 19:30 and no twilight period. Room temperature was $21 \pm 2{ }^{\circ} \mathrm{C}$ and humidity was regulated at $55 \pm 10 \%$. Mice received a sterilized (vacuum packed and irradiated) HFD [Western RD 829100, Special Diet Services, UK; $21.4 \%$ w/w crude fat (predominantly from milk) containing $0.2 \%$ cholesterol (42\% kcal from fats, energy density of $4.63 \mathrm{kcal} / \mathrm{g}$ )], or a control diet [AO3 rodent breeding diet, SAFE, France; $5.1 \%$ w/w crude fat (vegetable), (14\% kcal from fats, energy density of $3.2 \mathrm{kcal} / \mathrm{g})]$. All mice had ad libitum access to water and food. All experiments were performed according to protocols approved by the UK Home Office regulations, UK Animals (Scientific Procedures) Act of 1986.

Experimental design and high-fat-diet (HFD) protocol

Male mice were placed on the control diet at weaning (3 weeks of age) and were then either maintained on the control diet or transferred to the HFD at 4, 10, 12, or 14 weeks of age, as presented in Fig. 1. Cages of mice were randomly assigned to each of the five groups $(n=30$ per group). Body weight was measured weekly on the same day of the week until 16 weeks of age when the experiment was terminated. Body composition, plasma chemistry, and haematology were measured for all mice at 16 weeks of age. A subset of ten mice per group was selected for liver histopathology at 16 weeks of age. For each test, the experimental unit was an individual animal.

In a second experiment, two groups ( $n=30$ per group) of female mice received the same battery of tests (as above). One group was fed the control diet for the duration of the experiment and the other group started HFD at 14 weeks of age for a duration of 2 weeks. This experiment was terminated at 16 weeks of age.

Experimental procedures

Body composition/dual-energy X-ray absorptiometry (DEXA)

Mice were anaesthetised with ketamine hydrochloride (100 mg/kg, Ketaset $\AA$, Fort Dodge Animal Health)/xylazine hydrochloride $(10 \mathrm{mg} / \mathrm{kg}$, Rompun $\AA$, Bayer Animal Health). Body composition [fat mass ( $\mathrm{g}$ ), fat percentage estimate $(\%)$, lean mass $(\mathrm{g})$, bone mineral density $\left(\mathrm{g} / \mathrm{cm}^{2}\right)$, and bone mineral content (g)] was measured using a PIXImus densitometer in combination with Lunar 


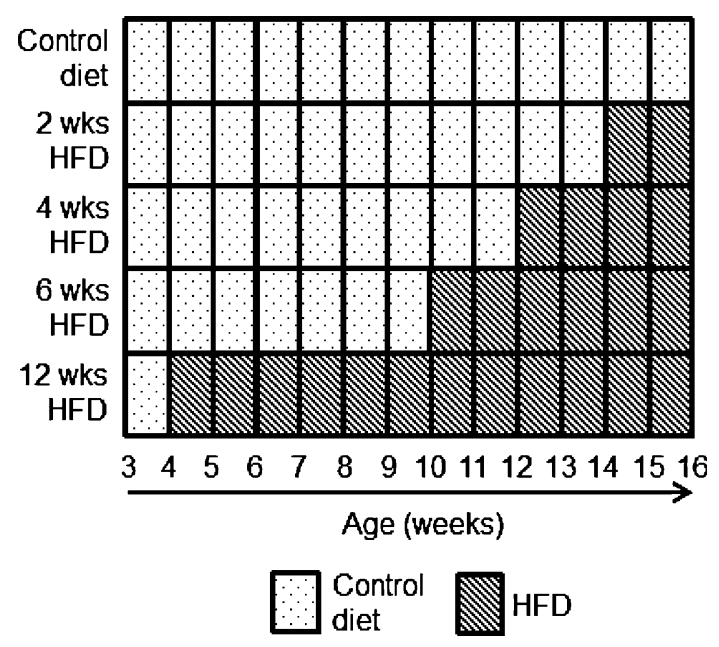

Fig. 1 Experimental design. Mice were placed on either an ad libitum control diet (dotted boxes) or on varying lengths of HFD (striped boxes) until the age of 16 weeks, at which point the mice were analysed for body composition and culled for organ harvest and blood collection

PIXImus2 2.1 software (GE Lunar, Madison, WI, USA). Quality control using a phantom was performed before imaging.

\section{Blood sample collection}

Blood was collected from animals in the fed state between 08:30 and 10:30. Whilst anaesthetised and without the need for a top-up dose of anaesthetic, blood was collected after DEXA by retro-orbital sinus puncture. $50 \mathrm{ml}$ of blood was collected into EDTA-coated paediatric tubes (Kabe Labortechnik GmbH, Numbrecht, Germany) for standard haematological analysis. The rest $(\sim 800 \mu \mathrm{l})$ was collected into heparinised paediatric tubes (Kabe Labortechnik) for plasma clinical chemistry analysis and insulin assay. Heparinised whole-blood samples were centrifuged at $5,000 \mathrm{rcf}$ for $10 \mathrm{~min}$ at $4{ }^{\circ} \mathrm{C}$, and the plasma was removed and stored at $4{ }^{\circ} \mathrm{C}$ until analysis, always within $1 \mathrm{~h}$ of collection.

\section{Laboratory analyses}

For clinical chemistry, plasma was assessed at room temperature for standard parameters on an Olympus AU400 analyser using kits and controls supplied by Beckman Coulter. A full list of the 28 parameters analysed is given in Supplementary Table 3a. Samples were also tested for haemolysis (Bernardi et al. 1996). Three parameters were measured on the Olympus AU400 analyser by kits not supplied by Beckman Coulter: nonesterified free fatty acids (NEFAC, Wako Chemical Inc., Richmond, VA, USA), glycerol (Randox Laboratories Ltd., UK) (Champy et al. 2004), and fructosamine (Roche Diagnostics $\mathrm{GmbH}$,
Mannheim, Germany). Internal quality controls were run on a daily basis and external quality controls were assessed at a 2-week interval and were supplied by UK NEQAS (University Hospitals Birmingham NHS Foundation, UK). Insulin was measured by Meso Scale Discovery array technology (Meso Scale Discovery, Rockville, MD, USA).

An automated electrical impedance cell counter (Scil Vet abc, Montpellier, France) was used to perform white blood cell counts $\left(\mathrm{WBC}, \times 10^{3} / \mu \mathrm{l}\right)$, red blood cell counts $\left(\mathrm{RBC}, \times 10^{6} / \mu \mathrm{l}\right)$, haematocrit $(\mathrm{HCT}, \%)$, mean cell volume (MCV, fl), mean corpuscular haemoglobin $(\mathrm{MCH}$, pg), mean corpuscular haemoglobin concentration (MCHC, $\mathrm{g} / \mathrm{dl})$, platelet counts $\left(\mathrm{PLT}, \times 10^{3} / \mu \mathrm{l}\right)$, and mean platelet volume (MPV, fl) measurements, whilst haemoglobin (HGB, g/dl) was measured by spectrophotometry.

\section{Liver pathology}

The liver was excised from ten mice from each group and weighed. Livers were immersion fixed in $10 \%$ neutral buffered formalin and were processed routinely to paraffin. Five-micrometre sections were cut and stained with haematoxylin and eosin (H\&E). Stained slides were analysed by a single experienced pathologist and the severity of macro- or microvesicular vacuolation was graded blind using a semiquantitative $0-5$ scale $(0=$ no vacuolation present, $5=$ all hepatocytes show vacuolation) (Shackelford et al. 2002). In the second study, liver samples from ten female mice fed either a control diet or 2 weeks of HFD were snap frozen, sectioned, and stained with Oil-Red-O (ORO) stain for lipids. The presence of ORO-stained vacuoles in hepatocytes was graded on a $0-4$ scale $(0=$ no vacuoles present, $1=$ occasional small lipid droplets, $2=$ mainly small lipid droplets in $<50 \%$ of cells, $3=$ most cells have small or large lipid droplets, and $4=$ virtually all cells have droplets mainly large). Slides were examined with an Olympus BX51 microscope and images were captured by an Olympus DP20 camera.

Statistical analysis

In accordance with the ARRIVE guidelines (Kilkenny et al. 2010), we have reported measures of precision, confidence, and $n$ to provide an indication of significance. Comparisons across groups of body weight, DEXA, clinical chemistry, haematology, and liver weight were performed by one-way analysis of variance (ANOVA). The assumptions of the analysis were assessed by the Shapiro-Wilk test of normality and Levene's test for homogeneity of variance. The result of Levene's test was used to determine the post hoc testing strategy. If not significant, Tukey's HSD post hoc testing was employed. If Levene's test was significant, the ANOVA was followed by Tamhane's T2 post hoc test for 
unequal variance. For all statistical tests, $p<0.05$ was considered statistically significant. Analysis was completed using SPSS for Windows v16 (SPSS Inc. Chicago, IL, USA) and the graphs were generated in GraphPad Prism 6 (GraphPad Software, San Diego, CA, USA). Weight curve data is given as mean \pm standard error of the mean (SEM). Data shown as a boxplot display whiskers extending to the furthest data point, which is no more than $1.5 \times$ the interquartile range. Outliers outside this range are shown as filled circles.

A significant result from an ANOVA was always accompanied by an $\omega^{2}$ value as a measure of effect size. Thresholds of $0.01,0.06$, and 0.14 were used for small, medium, and large effect sizes, respectively (Kirk 1996). Where significant differences were found in post hoc tests, Cohen's $d$ was calculated as a standardised measure of effect size when comparing two groups. The widely used thresholds for small, medium, and large effect sizes $(0.2,0.5$, and 0.8 ) were used to classify the size of the changes (Cohen 1988). A positive Cohen's $d$ indicates that the mean value for group 1 was higher than group 2 , and a negative result shows that the mean value for group 1 was lower than group 2 (where groups are defined in the Supplementary Tables).

\section{Results}

HFD effect on body weight and body composition

Percentage weight gain of the mice on the HFD and associated statistical analysis are shown in Supplementary Table 1a and $\mathrm{b}$. Overall, there was a significant and large $\left(p<0.001, \omega^{2}=0.34\right)$ effect of duration of HFD exposure on body weight (Fig. 2a) so that by week 16, body weight gains of all the HFD groups were different than that of the control group ( $p<0.01$ for all groups) (Fig. 2b). At 4 weeks of age, 1 week of HFD resulted in a mean weight gain of $28.8 \%$ compared to a gain of $19.9 \%$ for the control mice ( $p=0.002$, Cohen's $d=-0.99$ ). One week of HFD feeding produced a response similar to that of mice from the 2-week HFD group $(p<0.05, d=-0.81)$, the 4-week HFD group ( $p<0.001, d=-1.3$ ), and the 6-week HFD group $(p<0.001, d=-1.87)$. Notably, extended exposure to the HFD resulted in a plateau in weight gain after 7 weeks of HFD feeding ( $p>0.05$ for weekly $\%$ weight gain) for the 12-week HFD group. Therefore, B6N mice rapidly increase body weight upon administration of HFD, although with extended feeding, week-on-week weight gain eventually reaches a plateau.

Comparison of DEXA variables across the groups is given in Supplementary Table 2a and b. Over the entire dataset, HFD feeding produced a very large and significant increase in fat mass $\left(p<0.001, \omega^{2}=0.64\right)$, increasing
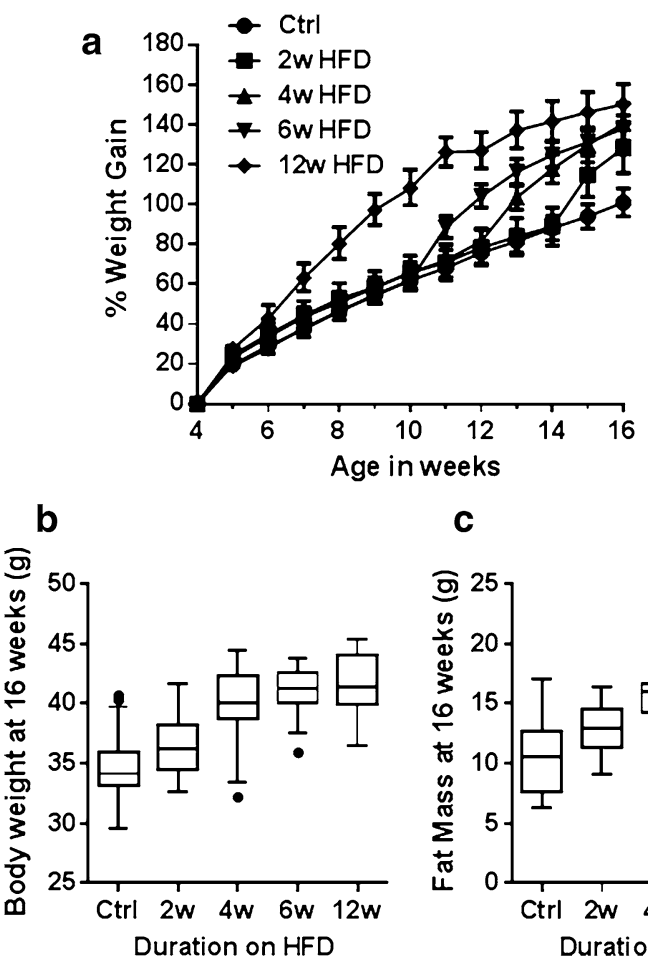

c

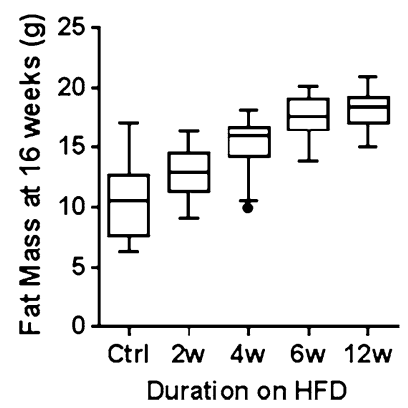

Fig. 2 Comparison of body weight of C57BL/6NTac male mice following varying durations of exposure to HFD. a Percentage body weight gain from 4 to 16 weeks of age relative to the starting body weight at 4 weeks of age which ranged from 12.2 to $20.3 \mathrm{~g}$ $($ mean $=16.9 \mathrm{~g})$. Data are presented as mean percentage weight gain \pm SEM. b Boxplot of terminal body weights at week 16 . Median, 25th percentile, and 75th percentile (box) and the lowest and highest data points still within $1.5 \times$ interquartile range (IQR) (whiskers) for each of the HFD durations are shown. Data points falling outside the $1.5 \times \mathrm{IQR}$ are considered outliers and represented with a filled circle. $\mathbf{c}$ Boxplot of terminal fat mass at 16 weeks of age as measured by DEXA

from $10.3 \mathrm{~g}$ in control mice to $18.1 \mathrm{~g}$ in mice exposed to 12 weeks of HFD (Fig. 2c). Lean mass was decreased over the dataset $\left(p<0.05, \omega^{2}=0.05\right)$, although post hoc analysis revealed no significant differences between experimental groups. Nose-to-tail base length was unchanged by exposure to HFD $(p=0.32)$. Bone mineral content (BMC) showed a significant increase in mice at all durations of HFD compared to the control diet $(p<0.001$, $\left.\omega^{2}=0.28\right)$, although BMC values for different HFD exposure lengths were similar (Supplementary Table $2 \mathrm{~b}$ ).

HFD effect on glucose and insulin metabolism

Non-fasted-state preanaesthesia tail tip glucose was not elevated in mice exposed to any length of HFD (Supplementary Table 3a, b). Assessment of postanaesthesia blood chemistry (Fig. 3a; Supplementary Table 3a, b) showed highly elevated plasma glucose (all sample mean $=24.7 \mathrm{mmol} / \mathrm{l}$ ), which was 

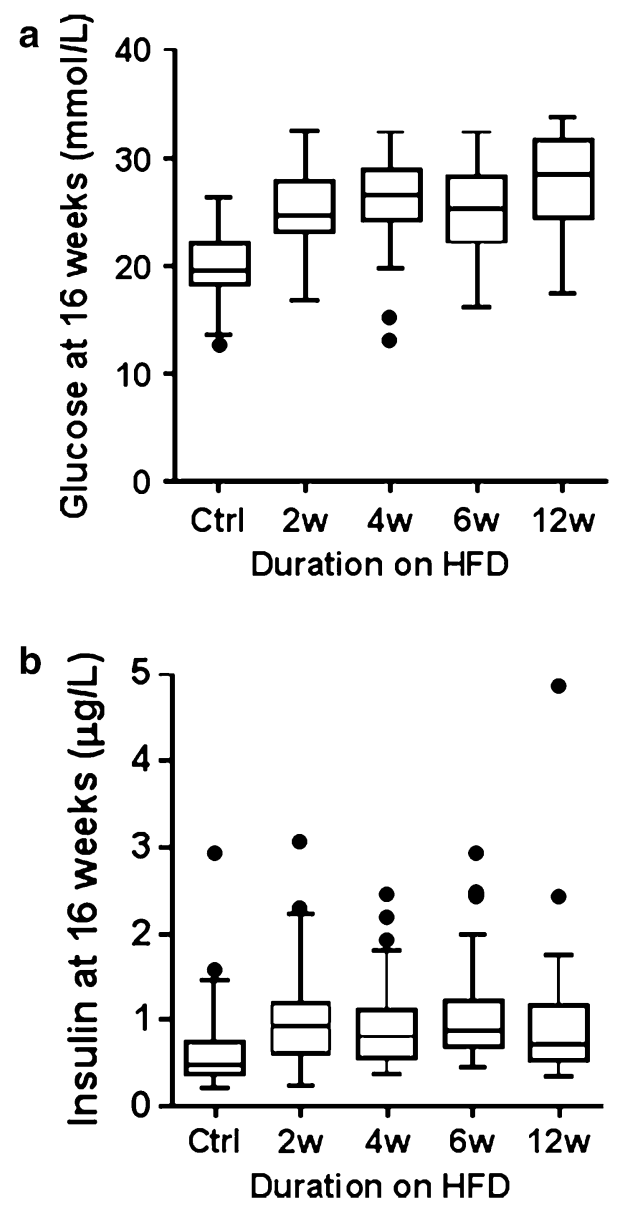

Fig. 3 Boxplots of metabolic variables of C57BL/6NTac male mice (16 weeks of age) following varying duration of exposure to HFD showing a post-anaesthesia plasma glucose concentration and b postanaesthesia plasma insulin concentration

likely due to a stress response known to be induced in B6J mice by the anaesthetic used (Brown et al. 2005). In the presence of this stress response, there was a significant difference in postanaesthesia plasma glucose between groups $\left(p<0.01, \omega^{2}=0.28\right)$. All HFD groups had statistically higher glucose than the control group $(p<0.001$ for all groups), but they were not significantly different from each other.

Plasma insulin levels were significantly different between the control group and each of the HFD groups $\left(p<0.05, \omega^{2}=0.12\right)$ (Fig. 3b). The mean insulin was $0.72 \mu \mathrm{g} / \mathrm{l}$ in the controls compared to $1.09 \mu \mathrm{g} / \mathrm{l}$ in mice fed HFD for 2 weeks, which represents a $50 \%$ increase, though it is lower than the levels observed in known diabetic models (Tonra et al. 1999). Insulin levels did not progressively increase with longer exposures of up to 12 weeks of HFD, which may have been predicted since HFD feeding typically leads to insulin resistance (Rossmeisl et al. 2003; West et al. 1992). However, the contribution of the anaesthetic to the unchanged plasma insulin levels cannot be ruled out (Saha et al. 2005).

HFD effect on plasma lipids

The plasma concentrations of total cholesterol, high-density lipoprotein cholesterol (HDL), and low-density lipoprotein cholesterol (LDL) were significantly increased in mice fed the HFD compared with those fed the control diet (Supplementary Table 3a, b; Fig. 4a, b). After just 2 weeks of HFD feeding, there was a significant elevation ( $p<0.001$ for all three variables) with very large Cohen's $d$ effect sizes of $-5.14,-5.21$, and -5.69 , respectively. These levels progressively increased as the mice had longer exposure to HFD, whilst plasma triglyceride levels in all HFD-fed groups significantly decreased compared to those fed the control diet ( $p<0.001$, Cohen's $d=2.76$ after just 2 weeks of HFD feeding, Fig. 4c). No effect of HFD exposure on non-esterified free fatty acid (NEFAC) plasma concentration was seen (Fig. 4d) when compared to the groups fed the control diet.

HFD effect on liver weight, macroscopic appearance, and histology

HFD resulted in a significantly increased liver weight compared to the control diet $\left(p<0.001, \omega^{2}=0.72\right)$ (Supplementary Table 4a, b; Fig. 5a). After 2 weeks of HFD, liver weight increased $11.8 \%$ compared to the control group ( $p=0.012$, Cohen's $d=-1.82$ ). The liver weight continued to increase further with increasing exposure to HFD.

Visually, mice fed 2 weeks of HFD had noticeably paler livers compared to control mice. The change in visual appearance became more dramatic with increasing duration of the HFD (data not shown). Representative H\&E- and ORO-stained sections from all HFD groups showed increased vacuolation (Fig. 5b-d) and lipid infiltration (Fig. 5e; Supplementary Table 11 for 2-week HFD feeding only). This correlates with the macroscopic observations of increased weight and pallor and reflected the liver lipid accumulation (Wouters et al. 2008). At all time points, both micro- and macrovesicular vacuolation was seen in some or all animals fed the HFD, with microvesicular vacuolation predominating at early time points and increasing macrovesicular vacuolation observed over time on the HFD (Table 1). At low severity grades, microvesicular vacuolation was seen predominantly in the centrilobular hepatocytes, extending to other zones with increased severity. Conversely, at low severity grades, macrovesicular vacuolation tended to be seen in the periportal hepatocytes, extending to other zones with increased severity. There was no evidence of increased inflammation or 

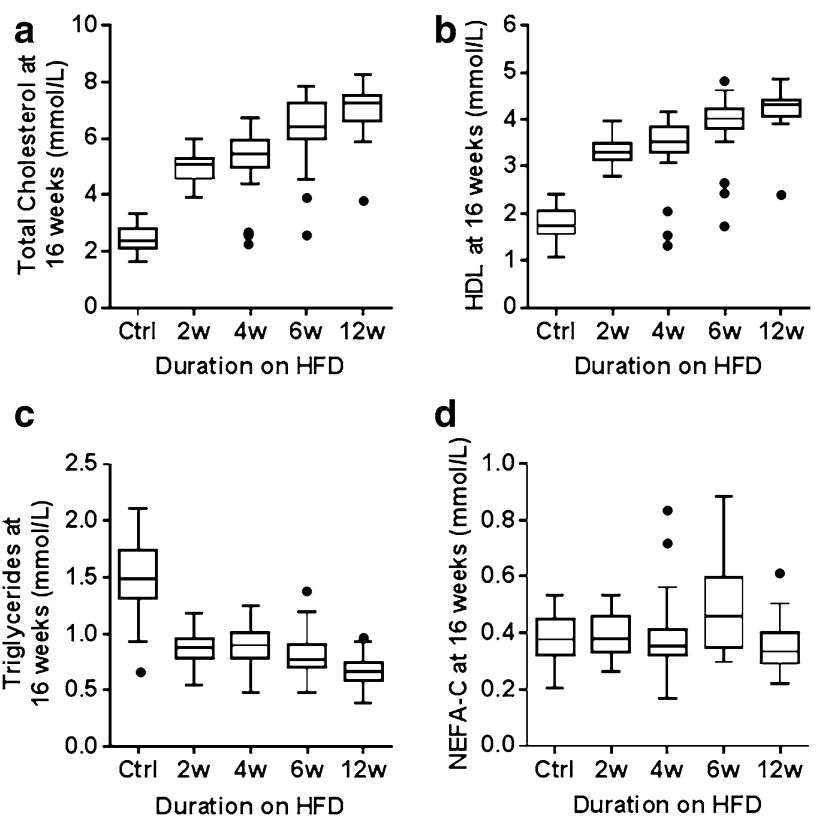

Fig. 4 Plasma lipid variables of C57BL/6NTac male mice (16 weeks of age) following varying duration of exposure to HFD. Boxplots of a total cholesterol, b high-density lipoprotein cholesterol (HDL), c triglycerides, and $\mathbf{d}$ nonesterified free fatty acids (NEFAC)

fibrosis in HFD-fed mice compared to controls at any time point.

\section{HFD effect on liver enzymes}

Plasma alanine aminotransferase (ALT) and aspartate aminotransferase (AST) are used in rats as markers for the evaluation of hepatic injury and the increase in individuals with hepatic steatosis (Ennulat et al. 2010). At 2 weeks of HFD feeding, there was a moderate but statistically nonsignificant $(p=0.10)$ increase in plasma ALT of $32 \%$ relative to the control group. Prolonged duration of HFD resulted in a progressive increase that became significant at 4 weeks of HFD $(p<0.001, d=-1.49)$ (Supplementary Table 3a, b). AST significantly increased at just 2 weeks of HFD by $44.9 \%(p<0.001, d=-1.41)$; however, this marker has a high basal level (Tetri et al. 2008), and this increase could also be due to an HFD-induced increase in AST production from nonhepatic sources. Plasma lactate dehydrogenase $(\mathrm{LDH})$ levels progressively increase with length of exposure to HFD. At 2 weeks of HFD feeding, there was a moderate but statistically nonsignificant ( $p=0.709)$ increase of $12 \%$ in plasma LDH relative to the control group. Prolonged duration of HFD resulted in a progressive increase which became significant at 4 weeks of HFD ( $p=0.020, d=-1.08$ ) (Supplementary Table 3a, b). However, LDH is not considered suitable for use as a diagnostic marker of liver response to HFD since it is highly variable presumably because it is an isoenzyme.
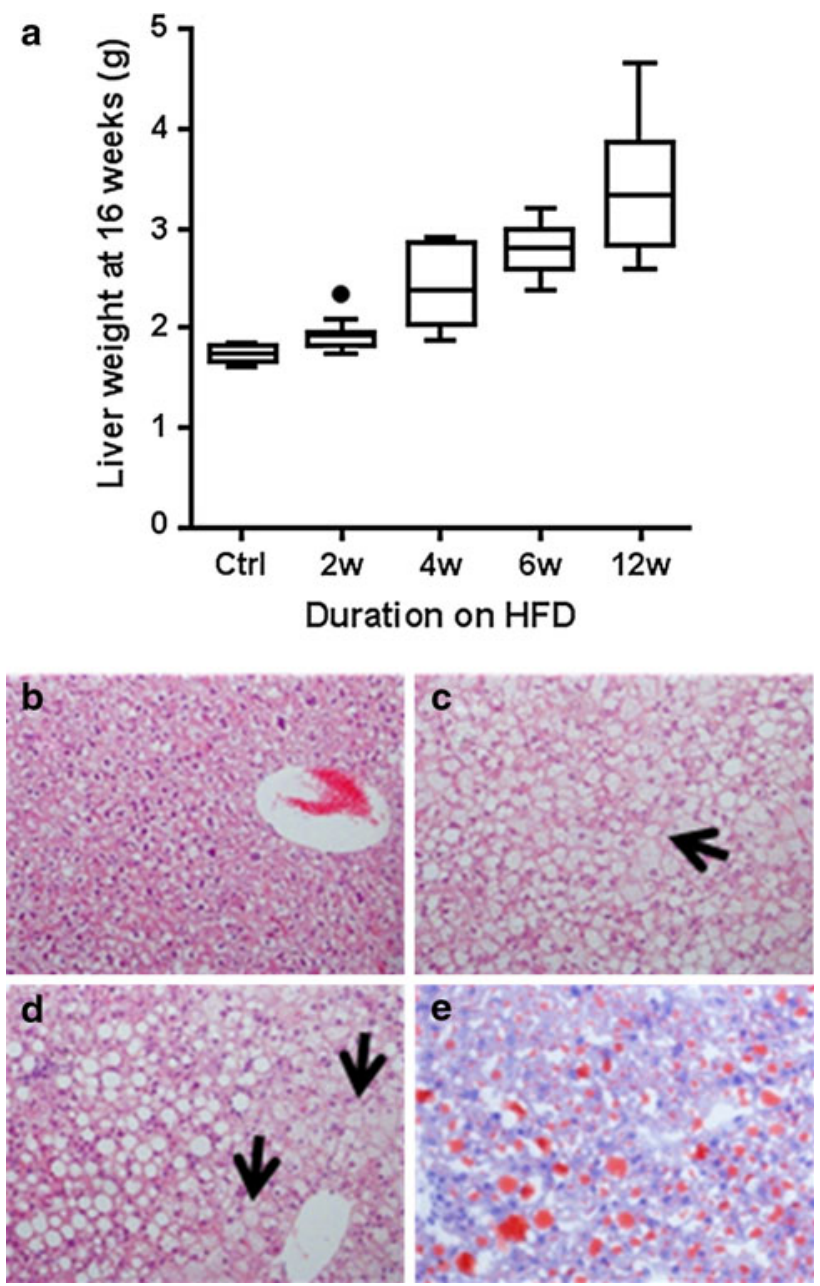

Fig. 5 Analysis of liver from C57BL/6NTac male mice following varying duration of exposure to HFD. a Effect of varying exposure to HFD on liver weight (wet weight) of C57BL/6NTac male mice at 16 weeks of age. b-e Representative photomicrographs of the livers (100× magnification) from 16-week-old mice. b H\&E-stained section from control liver showing no vacuolation. c H\&E-stained section showing hepatocytes enlarged by microvesicular vacuoles (as shown by arrow). d H\&E-stained section demonstrating hepatocytes in portal area containing macrovesicular vacuoles (as shown by arrow). e Oil-red-O-stained section demonstrating positive staining for lipid in macro and microvesicular vacuoles

Effect of varying exposure to HFD on whole-blood counts and platelets

HFD increased WBC counts after 12 weeks $(p=0.002$, Cohen's $d=-1.02$ ) (Supplementary Table 5a, b). Platelet count was decreased in mice fed HFD for 4,6 , and 12 weeks $(p<0.01)$ when compared with either the control diet or 2 weeks' exposure to HFD (Fig. 6). These results suggest that longer exposures $(\geq 4$ weeks) to HFD have a depressive effect on platelet counts, with large Cohen's $d$ effect sizes of $1.06,1.29$, and 1.77 for 4,6 , and 12 weeks of HFD, respectively, compared to control mice. 
Table 1 Incidence table of severity of micro- and macrovesicular vacuolation in livers from mice fed HFD for up to 12 weeks for ten representative male mice per group

\begin{tabular}{ccclll}
\hline Grade & Control & $\begin{array}{l}2 \text { Weeks } \\
\text { HFD }\end{array}$ & $\begin{array}{l}4 \text { Weeks } \\
\text { HFD }\end{array}$ & $\begin{array}{l}6 \text { Weeks } \\
\text { HFD }\end{array}$ & $\begin{array}{l}\text { 12 Weeks } \\
\text { HFD }\end{array}$ \\
\hline \multicolumn{7}{l}{ Microvesicular vacuolation } \\
0 & 10 & 0 & 2 & 0 & 0 \\
1 & 0 & 3 & 0 & 0 & 0 \\
2 & 0 & 6 & 2 & 0 & 0 \\
3 & 0 & 1 & 2 & 4 & 1 \\
4 & 0 & 0 & 3 & 5 & 5 \\
5 & 0 & 0 & 0 & 1 & 4 \\
Macrovesicular vacuolation & & & \\
0 & 10 & 4 & 4 & 4 & 0 \\
1 & 0 & 5 & 2 & 1 & 0 \\
2 & 0 & 1 & 3 & 1 & 2 \\
3 & 0 & 0 & 0 & 4 & 6 \\
4 & 0 & 0 & 1 & 0 & 1 \\
\hline
\end{tabular}

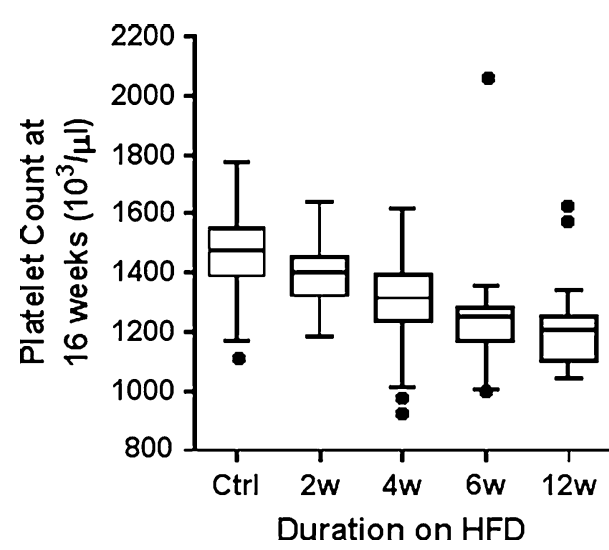

Fig. 6 Effect of varying exposure to HFD on platelet counts of male mice at 16 weeks of age

Effect of varying exposure to HFD on female mice

Female mice [weight range $=12.2-17.3 \mathrm{~g}$ at 4 weeks of age $($ mean $=14.7 \mathrm{~g})]$ fed the HFD for just 2 weeks had a similar response to the diet as male mice, including the changes seen in body weight, fat mass, liver enzymes, plasma lipids, and cell blood counts (Supplementary Tables 6-11). The effect was comparable to the male mice fed for the same period; however, these similarities may not persist following extended exposure to HFD (Spruss et al. 2012).

Comparison of published metabolic indicators in HFDfed B6N and B6J mice

The results of this study were placed in context with published data on B6N or B6J mice exposed to a HFD (varying compositions) for a broadly similar time period (up to 6 months duration) (Table 2). Five phenotypic categories were investigated: body weight/composition, plasma chemistry metabolic parameters, plasma chemistry liver parameters, complete blood counts, and liver pathology. With the exception of plasma triglyceride levels, which were variably reported in the literature, this comparison showed that for these broad phenotypic categories, B6N and B6J mice respond to HFD exposure with similar trends, e.g., increased weight gain, development of liver steatosis, presence of subsets of liver enzymes in plasma, and similar trends in plasma metabolic parameters.

\section{Discussion}

Genetically modified mouse models provide a powerful tool to investigate basic biological and mechanistic questions in a whole-organism setting. Given the genetic and phenotypic diversity of different mouse strains and substrains, understanding whether a particular strain of mouse will be appropriate for a given phenotypic test is essential. Here, we provide baseline data for B6N mice exposed to a HFD for a range of durations. This strain is particularly topical given the growing resource of targeted ES cells generated by the IKMC and the commitment by members of the International Mouse Phenotyping Consortium (http://www.mousephenotype.org/) to characterise B6N mice with disrupted alleles for every known and predicted mouse gene.

Similar to B6J mice, the B6N strain is sensitive to a HFD and recapitulates some of the key features of metabolic syndrome such as obesity, hyperinsulinaemia, elevated cholesterol, and hepatic lipid deposition (Table 2). As little as 1 week on a HFD can increase body weight to a greater extent than our control diet. Generally, fat mass increased in proportion to the length of exposure to the HFD, similar to that previously reported in other mouse strains (West et al. 1995). In the B6N strain, the rate of body weight gain was lower at 6 and 12 weeks of HFD exposure compared with shorter HFD exposures. From the perspective of designing phenotyping procedures, our data suggest that careful consideration is needed to identify the optimal age and duration of feeding with a HFD for each strain to obtain the mice in the desired physiological condition. As expected, we saw changes in multiple clinical chemistry parameters associated with metabolic syndrome, including elevated total, HDL, and LDL cholesterol, as well as increased insulin (Table 2). Consistent with our observations, previous studies examining the effect of HFD on $\mathrm{C} 57 \mathrm{BL} / 6$ mice have shown that triglycerides are reduced with HFD (Biddinger et al. 2005; Guo et al. 2009). As hypothesized in these papers, the combination of liver 


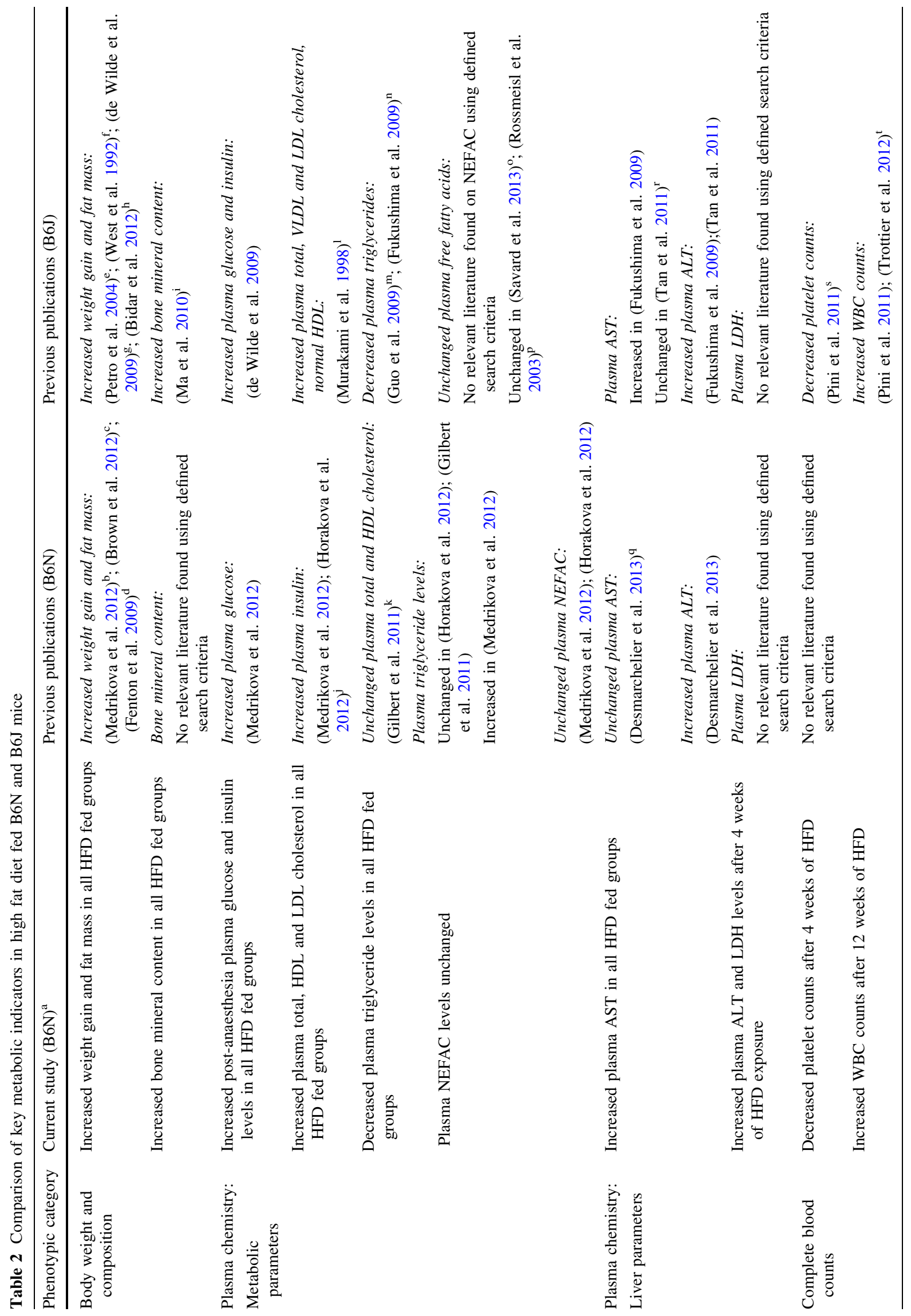




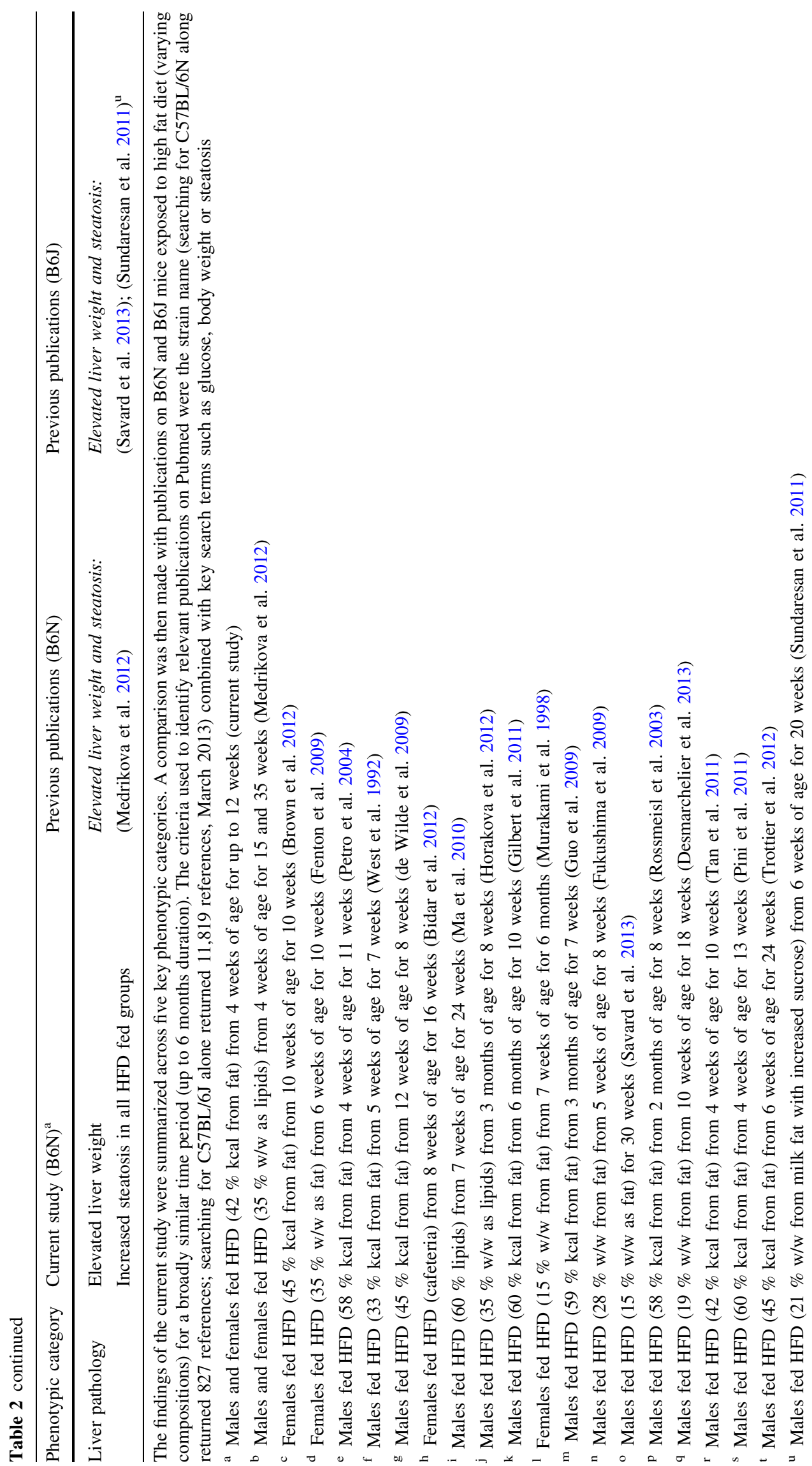


steatosis and reduced plasma triglycerides might reflect a HFD-induced partitioning of lipids into the liver, either by reduced hepatic triglyceride production or by increased triglyceride clearance. Surprisingly, levels of fructosamine were reduced in our HFD-fed B6N mice. Fructosamine is used in a manner similar to that of glycated haemoglobin $\left(\mathrm{HbA}_{1 \mathrm{c}}\right)$, i.e., as a marker for average plasma glucose concentration over time. Whilst $\mathrm{HbA}_{1 \mathrm{c}}$ reflects 6-8-week glucose turnover, fructosamine reflects a shorter window of 1-3 weeks (Armbruster 1987). Glucose levels measured preanaesthesia were not increased with HFD, which may account for the lack of an increase in fructosamine that was observed.

In humans, the rising incidence of NAFLD is in line with increased prevalence of metabolic syndrome (Cusi 2012), and obesity, type 2 diabetes, hyperlipidaemia, and hypertension are all thought to be risk factors for developing NAFLD (Angulo 2002). We have extended observations from liver histology seen in B6J mice exposed to high-calorie diets (Gaemers et al. 2011; Sundaresan et al. 2011 ) to the B6N background (Table 2). In B6N mice liver parameters were strikingly affected by a HFD; increased liver weights and histopathological changes could be detected after 2 weeks of HFD, and elevated plasma levels of liver enzymes associated with hepatic damage were seen after 4 weeks of HFD. The effect of a HFD on liver parameters was similar in both males and females. Liver pathology progressively worsened with the duration of exposure to HFD in a pattern that was reminiscent of lipid deposition in human patients. However, liver pathology did not progress to inflammation or fibrosis even after 12 weeks of HFD, suggesting that the changes could potentially be reversible. There are many mouse models of NAFLD (Anstee and Goldin 2006); however, the majority of them do not develop fibrosis unless there is a second (Day and James 1998) or multiple additional insults (Tilg et al. 2011). B6N mice on a HFD displayed hypercholesterolemia in both HDL and LDL fractions but decreased plasma triglycerides. Conversely, in humans, NAFLD is associated with hypercholesterolemia and hypertriglyceridemia, together with reduced levels of HDL (Chatrath et al. 2012). There are intrinsic differences between mouse and human lipid metabolism (overviewed by Getz 2007). For example, the major lipoprotein in humans is LDL, whereas it is HDL in mice, with whole-body cholesterol turnover being around tenfold higher in mice than humans. Genetic differences also exist such as cholesterol ester transfer protein being present in humans but not mice, and ApoA-I synthesis being increased by PPAR $\alpha$ in humans but decreased in mice. All of these facts may impact on the translation of NAFLD mouse models to human patients. In contrast, despite NAFLD being subclinical for years, liver enzymes and other markers of liver function are elevated in
$90 \%$ of cases (Angulo 2002), which fits with our findings in B6N mice. ALT is a clinically important marker for the diagnosis of hepatocellular injury (Thrall et al. 2004). AST and ALP are also used, although, due to their more widespread pattern of expression, they are less specific for liver and may indicate injury to other organ systems. In the context of increased liver steatosis, our blood enzyme results indicate that the liver is likely to be the main site of tissue damage caused by our HFD protocol. Potentially, therefore, HFD-fed B6N mice may capture some of the earliest features of NAFLD that are typically silent in human patients for years prior to diagnosis.

Outside of metabolism, we found that HFD treatment of B6N mice resulted in significant haematological changes, including a decreased platelet count that may indicate enhanced platelet reactivity and dynamic coagulation, and a predisposition to develop atherosclerosis (Lowenstein 2011). It is known that platelet count is reduced in patients with NAFLD and is being examined as a diagnostic biomarker for progression of the disease (Kaneda et al. 2006; Ozhan et al. 2010). Therefore, platelet counts in the HFD B6N mice may become a translatable marker for NAFLD progression and treatment in preclinical studies. WBC count was also found to increase after 12 weeks of HFD exposure. Consistent with this, extended HFD treatment in C57BL/6J mice resulted in an increased number of WBCs (Pini et al. 2011; Trottier et al. 2012) (Table 2).

Current NAFLD models include genetically modified mice $\left(\right.$ Mat1a $^{-/-}$, Pten $^{-/-}$, Lepr $\left.^{d b / d b}\right)$ or mice that undergo nutritional challenges (methionine/choline-deficient diets) (Hebbard and George 2011). Data presented here suggest that the $\mathrm{B} 6 \mathrm{~N}$ genetic background, which has become the preferred strain for generating genetically modified mouse models, is appropriate for studies examining the early stages of liver steatosis and for generation of genetically engineered mice with a predisposition to NAFLD.

Acknowledgments We thank staff from the Sanger Institute's Research Support Facility and Mouse Informatics Group for their excellent support, Keith Burling for measuring the insulin concentration, and Dr. Peter Voshol for helpful discussions. This work was funded by the Wellcome Trust (Grant No. WT077157/Z/05/Z).

Open Access This article is distributed under the terms of the Creative Commons Attribution License which permits any use, distribution, and reproduction in any medium, provided the original author(s) and the source are credited.

\section{References}

Angulo P (2002) Nonalcoholic fatty liver disease. N Engl J Med 346:1221-1231

Anstee QM, Goldin RD (2006) Mouse models in non-alcoholic fatty liver disease and steatohepatitis research. Int $\mathbf{J}$ Exp Pathol $87: 1-16$ 
Armbruster DA (1987) Fructosamine: structure, analysis, and clinical usefulness. Clin Chem 33:2153-2163

Bachmanov AA, Reed DR, Tordoff MG, Price RA, Beauchamp GK (2001) Nutrient preference and diet-induced adiposity in C57BL/ 6ByJ and 129P3/J mice. Physiol Behav 72:603-613

Bernardi C, Monetal D, Brughera M, Salvo M, Lamparelli D, Mazué G, Iatropoulos MJ (1996) Haematology and clinical chemistry in rats: comparison of different blood collection sites. Comp Haematol Int 6:160-166

Bidar AW, Ploj K, Lelliott C, Nelander K, Winzell MS, Böttcher G, Oscarsson J, Storlien L, Hockings PD (2012) In vivo imaging of lipid storage and regression in diet-induced obesity during nutrition manipulation. Am J Physiol Endocrinol Metab 303:E1287-E1295

Biddinger SB, Almind K, Miyazaki M, Kokkotou E, Ntambi JM, Kahn CR (2005) Effects of diet and genetic background on sterol regulatory element-binding protein-1c, stearoyl-CoA desaturase 1 , and the development of the metabolic syndrome. Diabetes 54:1314-1323

Brown ET, Umino Y, Loi T, Solessio E, Barlow R (2005) Anesthesia can cause sustained hyperglycemia in C57/BL6J mice. Vis Neurosci 22:615-618

Brown JD, Naples SP, Booth FW (2012) Effects of voluntary running on oxygen consumption, RQ, and energy expenditure during primary prevention of diet-induced obesity in C57BL/6N mice. J Appl Physiol 113:473-478

Bryant CD, Zhang NN, Sokoloff G, Fanselow MS, Ennes HS, Palmer AA, McRoberts JA (2008) Behavioral differences among C57BL/6 substrains: implications for transgenic and knockout studies. J Neurogenet 22:315-331

Champy MF, Selloum M, Piard L, Zeitler V, Caradec C, Chambon P, Auwerx J (2004) Mouse functional genomics requires standardization of mouse handling and housing conditions. Mamm Genome 15:768-783

Chatrath H, Vuppalanchi R, Chalasani N (2012) Dyslipidemia in patients with nonalcoholic fatty liver disease. Semin Liver Dis 32:022-029

Cohen J (1988) Statistical power analysis for the behavioral sciences. Lawrence Earlbaum Associates, Mahwah

Cusi K (2012) Role of obesity and lipotoxicity in the development of nonalcoholic steatohepatitis: pathophysiology and clinical implications. Gastroenterology 142(711-725):e716

Datta S, Turner D, Singh R, Ruest LB, Pierce WM, Knudsen TB (2008) Fetal alcohol syndrome (FAS) in C57BL/6 mice detected through proteomics screening of the amniotic fluid. Birth Defects Res A Clin Mol Teratol 82:177-186

Day CP, James OFW (1998) Steatohepatitis: a tale of two "hits"? Gastroenterology 114:842-845

de Wilde J, Smit E, Mohren R, Boekschoten MV, de Groot P, van den Berg SAA, Bijland S, Voshol PJ, van Dijk KW, de Wit NWJ, Bunschoten A, Schaart G, Hulshof MFM, Mariman ECM (2009) An 8-week high-fat diet induces obesity and insulin resistance with small changes in the muscle transcriptome of C57BL/6J mice. J Nutrigenet Nutrigenomics 2:280-291

Desmarchelier C, Ludwig T, Scheundel R, Rink N, Bader BL, Klingenspor M, Daniel H (2013) Diet-induced obesity in ad libitum-fed mice: food texture overrides the effect of macronutrient composition. Br J Nutr 109(8):1518-1527

Eisener-Dorman AF, Lawrence DA, Bolivar VJ (2009) Cautionary insights on knockout mouse studies: the gene or not the gene? Brain Behav Immun 23:318-324

Ennulat D, Magid-Slav M, Rehm S, Tatsuoka KS (2010) Diagnostic performance of traditional hepatobiliary biomarkers of druginduced liver injury in the rat. Toxicol Sci 116:397-412

Fenton JI, Nuñez NP, Yakar S, Perkins SN, Hord NG, Hursting SD (2009) Diet-induced adiposity alters the serum profile of inflammation in C57BL/6N mice as measured by antibody array. Diabetes Obes Metab 11:343-354

Freeman HC, Hugill A, Dear NT, Ashcroft FM, Cox RD (2006) Deletion of nicotinamide nucleotide transhydrogenase. Diabetes 55:2153-2156

Fukushima Y, Kasuga M, Nakao K, Shimomura I, Matsuzawa Y (2009) Effects of coffee on inflammatory cytokine gene expression in mice fed high-fat diets. J Agric Food Chem 57:11100-11105

Gaemers IC, Stallen JM, Kunne C, Wallner C, van Werven J, Nederveen A, Lamers WH (2011) Lipotoxicity and steatohepatitis in an overfed mouse model for non-alcoholic fatty liver disease. Biochim Biophys Acta 1812:447-458

Getz GS (2007) Overview of murine atherosclerosis series. Curr Drug Targets 8:1144-1149

Gilbert ER, Fu Z, Liu D (2011) Development of a nongenetic mouse model of type 2 diabetes. Exp Diabetes Res 2011:12

Guan C, Ye C, Yang X, Gao J (2010) A review of current large-scale mouse knockout efforts. Genesis 48:73-85

Guo J, Jou W, Gavrilova O, Hall KD (2009) Persistent diet-induced obesity in male $\mathrm{C} 57 \mathrm{BL} / 6$ mice resulting from temporary obesogenic diets. PLoS ONE 4:e5370

Hebbard L, George J (2011) Animal models of nonalcoholic fatty liver disease. Nat Rev Gastroenterol Hepatol 8:35-44

Horakova O, Medrikova D, van Schothorst EM, Bunschoten A, Flachs P, Kus V, Kuda O, Bardova K, Janovska P, Hensler M, Rossmeisl M, Wang-Sattler R, Prehn C, Adamski J, Illig T, Keijer J, Kopecky J (2012) Preservation of metabolic flexibility in skeletal muscle by a combined use of n-3 PUFA and rosiglitazone in dietary obese mice. PLoS ONE 7:e43764

Kaneda H, Hashimoto E, Yatsuji S, Tokushige K, Shiratori K (2006) Hyaluronic acid levels can predict severe fibrosis and platelet counts can predict cirrhosis in patients with nonalcoholic fatty liver disease. J Gastroenterol Hepatol 21:1459-1465

Keane TM, Goodstadt L, Danecek P, White MA, Wong K, Yalcin B, Heger A, Agam A, Slater G, Goodson M, Furlotte NA, Eskin E, Nellaker C, Whitley H, Cleak J, Janowitz D, Hernandez-Pliego P, Edwards A, Belgard TG, Oliver PL, McIntyre RE, Bhomra A, Nicod J, Gan X, Yuan W, van der Weyden L, Steward CA, Bala S, Stalker J, Mott R, Durbin R, Jackson IJ, Czechanski A, Guerra-Assuncao JA, Donahue LR, Reinholdt LG, Payseur BA, Ponting CP, Birney E, Flint J, Adams DJ (2011) Mouse genomic variation and its effect on phenotypes and gene regulation. Nature 477:289-294

Khisti RT, Wolstenholme J, Shelton KL, Miles MF (2006) Characterization of the ethanol-deprivation effect in substrains of C57BL/6 mice. Alcohol 40:119-126

Kilkenny C, Browne WJ, Cuthill IC, Emerson M, Altman DG (2010) Improving bioscience research reporting: the ARRIVE guidelines for reporting animal research. PLoS Biol 8:e1000412

Kirk RE (1996) Practical significance: a concept whose time has come. Educ Psychol Meas 56:746-759

Lowenstein CJ (2011) Vav-Vav-Vav-voom! Blood 117:5557-5559

Ma H, Torvinen S, Silvennoinen M, Rinnankoski-Tuikka R, Kainulainen H, Morko J, Peng Z, Kujala U, Rahkila P, Suominen H (2010) Effects of diet-induced obesity and voluntary wheel running on bone properties in young male C57BL/6J mice. Calcif Tissue Int 86:411-419

Mattapallil MJ, Wawrousek EF, Chan CC, Zhao H, Roychoudhury J, Ferguson TA, Caspi RR (2012) The Rd8 mutation of the Crbl gene is present in vendor lines of C57BL/6N mice and embryonic stem cells, and confounds ocular induced mutant phenotypes. Invest Ophthalmol Vis Sci 53:2921-2927

Medrikova D, Jilkova ZM, Bardova K, Janovska P, Rossmeisl M, Kopecky J (2012) Sex differences during the course of dietinduced obesity in mice: adipose tissue expandability and glycemic control. Int J Obes 36:262-272 
Murakami S, Kondo-Ohta Y, Tomisawa K (1998) Improvement in cholesterol metabolism in mice given chronic treatment of taurine and fed a high-fat diet. Life Sci 64:83-91

Ozhan H, Aydin M, Yazici M, Yazgan O, Basar C, Gungor A, Onder E (2010) Mean platelet volume in patients with non-alcoholic fatty liver disease. Platelets 21:29-32

Petro AE, Cotter J, Cooper DA, Peters JC, Surwit SJ, Surwit RS (2004) Fat, carbohydrate, and calories in the development of diabetes and obesity in the C57BL/6J mouse. Metabolism 53: 454-457

Pettitt SJ, Liang Q, Rairdan XY, Moran JL, Prosser HM, Beier DR, Lloyd KC, Bradley A, Skarnes WC (2009) Agouti C57BL/6N embryonic stem cells for mouse genetic resources. Nat Methods 6:493-495

Pini M, Rhodes DH, Fantuzzi G (2011) Hematological and acutephase responses to diet-induced obesity in IL-6 KO mice. Cytokine 56:708-716

Ramírez-Solis R, Ryder E, Houghton R, White JK, Bottomley J (2012) Large-scale mouse knockouts and phenotypes. Wiley Interdiscip Rev Syst Biol Med 4(6):547-563

Rossmeisl M, Rim JS, Koza RA, Kozak LP (2003) Variation in type 2 diabetes-related traits in mouse strains susceptible to dietinduced obesity. Diabetes 52:1958-1966

Saha JK, Xia JQ, Grondin JM, Engle SK, Jakubowski JA (2005) Acute hyperglycemia induced by ketamine/xylazine anesthesia in rats: Mechanisms and implications for preclinical models. Exp Biol Med 230:777-784

Savard C, Tartaglione EV, Kuver R, Haigh WG, Farrell GC, Subramanian S, Chait A, Yeh MM, Quinn LS, Ioannou GN (2013) Synergistic interaction of dietary cholesterol and dietary fat in inducing experimental steatohepatitis. Hepatology 57: $81-92$

Seong E, Saunders TL, Stewart CL, Burmeister M (2004) To knockout in 129 or in C57BL/6: that is the question. Trends Genet 20:59-62

Shackelford C, Long G, Wolf J, Okerberg C, Herbert R (2002) Qualitative and quantitative analysis of nonneoplastic lesions in toxicology studies. Toxicol Pathol 30:93-96

Simpson EM, Linder CC, Sargent EE, Davisson MT, Mobraaten LE, Sharp JJ (1997) Genetic variation among 129 substrains and its importance for targeted mutagenesis in mice. Nat Genet 16: $19-27$

Skarnes WC, Rosen B, West AP, Koutsourakis M, Bushell W, Iyer V, Mujica AO, Thomas M, Harrow J, Cox T, Jackson D, Severin J, Biggs P, Fu J, Nefedov M, de Jong PJ, Stewart AF, Bradley A (2011) A conditional knockout resource for the genome-wide study of mouse gene function. Nature 474:337-342

Spruss A, Henkel J, Kanuri G, Blank D, Püschel GP, Bischoff SC, Bergheim I (2012) Female mice are more susceptible to nonalcoholic fatty liver disease: sex-specific regulation of the hepatic AMP-activated protein kinase-plasminogen activator inhibitor 1 cascade, but not the hepatic endotoxin response. Mol Med 18:1346-1355

Stickel F, Hellerbrand C (2010) Non-alcoholic fatty liver disease as a risk factor for hepatocellular carcinoma: mechanisms and implications. Gut 59:1303-1307
Stiedl O, Radulovic J, Lohmann R, Birkenfeld K, Palve M, Kammermeier J, Sananbenesi F, Spiess J (1999) Strain and substrain differences in context- and tone-dependent fear conditioning of inbred mice. Behav Brain Res 104:1-12

Sundaresan S, Vijayagopal P, Mills N, Imrhan V, Prasad C (2011) A mouse model for nonalcoholic steatohepatitis. J Nutr Biochem 22:979-984

Tan M, Schmidt RH, Beier JI, Watson WH, Zhong H, States JC, Arteel GE (2011) Chronic subhepatotoxic exposure to arsenic enhances hepatic injury caused by high fat diet in mice. Toxicol Appl Pharmacol 257:356-364

Tetri LH, Basaranoglu M, Brunt EM, Yerian LM, NeuschwanderTetri BA (2008) Severe NAFLD with hepatic necroinflammatory changes in mice fed trans fats and a high-fructose corn syrup equivalent. Am J Physiol Gastrointest Liver Physiol 295:G987G995

Thrall MA, Baker DC, Campbell TW, DeNicola D, Fettman MJ, Lassen ED, Rebar A, Weiser G (2004) Veterinary hematology and clinical chemistry. Blackwell, Ames

Tilg H, Moschen AR, Kaneider NC (2011) Pathways of liver injury in alcoholic liver disease. J Hepatol 55:1159-1161

Tonra JR, Ono M, Liu X, Garcia K, Jackson C, Yancopoulos GD, Wiegand SJ, Wong V (1999) Brain-derived neurotrophic factor improves blood glucose control and alleviates fasting hyperglycemia in C57BLKS-Lepr(db)/lepr(db) mice. Diabetes 48: 588-594

Toye A, Lippiat J, Proks P, Shimomura K, Bentley L, Hugill A, Mijat V, Goldsworthy M, Moir L, Haynes A, Quarterman J, Freeman H, Ashcroft F, Cox R (2005) A genetic and physiological study of impaired glucose homeostasis control in C57BL/6J mice. Diabetologia 48:675-686

Trottier MD, Naaz A, Li Y, Fraker PJ (2012) Enhancement of hematopoiesis and lymphopoiesis in diet-induced obese mice. Proc Natl Acad Sci USA 109:7622-7629

Waterston RH (2002) Initial sequencing and comparative analysis of the mouse genome. Nature 420:520-562

West DB, Boozer CN, Moody DL, Atkinson RL (1992) Dietary obesity in nine inbred mouse strains. Am J Physiol 262:R1025R1032

West DB, Waguespack J, McCollister S (1995) Dietary obesity in the mouse: interaction of strain with diet composition. Am J Physiol 268:R658-R665

Wouters K, van Gorp PJ, Bieghs V, Gijbels MJ, Duimel H, Lutjohann D, Kerksiek A, van Kruchten R, Maeda N, Staels B, van Bilsen M, Shiri-Sverdlov R, Hofker MH (2008) Dietary cholesterol, rather than liver steatosis, leads to hepatic inflammation in hyperlipidemic mouse models of nonalcoholic steatohepatitis. Hepatology 48:474-486

Yalcin B, Wong K, Agam A, Goodson M, Keane TM, Gan X, Nellaker C, Goodstadt L, Nicod J, Bhomra A, Hernandez-Pliego P, Whitley H, Cleak J, Dutton R, Janowitz D, Mott R, Adams DJ, Flint J (2011) Sequence-based characterization of structural variation in the mouse genome. Nature 477:326-329 